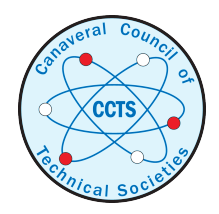

The Space Congress $®$ Proceedings

2012 (42nd) A New Beginning

Dec 7th, 8:30 AM

\title{
NASA Ground and Launch Systems Processing Technology Area Roadmap
}

Nancy Zeitlin

presenter

Gregory Clements

KSC

Barbara Brown

$A R C$

Stan Schaefer

JSC

Mike Fawcett

JSC

Follow this and additional works at: https://commons.erau.edu/space-congress-proceedings

\section{Scholarly Commons Citation}

Zeitlin, Nancy; Clements, Gregory; Brown, Barbara; Schaefer, Stan; and Fawcett, Mike, "NASA Ground and Launch Systems Processing Technology Area Roadmap" (2012). The Space Congress ${ }^{\circledR}$ Proceedings. 16. https://commons.erau.edu/space-congress-proceedings/proceedings-2012-42nd/december-07-2012/16

This Event is brought to you for free and open access by the Conferences at Scholarly Commons. It has been accepted for inclusion in The Space Congress ${ }^{\circledR}$ Proceedings by an authorized administrator of Scholarly Commons. For more information, please contact commons@erau.edu.

EMBRYRIDDLE Aeronautical University SCHOLARLY COMMONS 


\section{NASA Ground \& Launch Systems \\ Processing Technology Area Roadmap}

Nancy Zeitlin, presenter

Co-Authors:

Gregory Clements/KSC, Barbara Brown/ARC, Stan Schaefer/JSC, Mike Fawcett/JSC

December 7, 2012 


\section{NAsA NASA Space Technology Roadmap Technology Area Breakdown Structure}

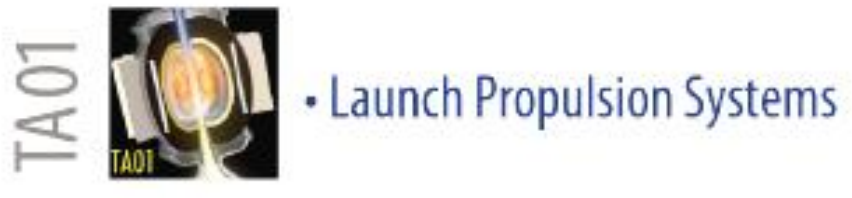

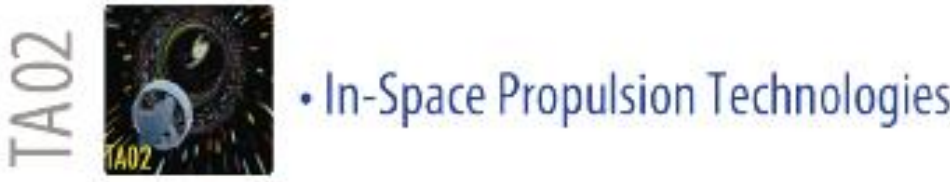

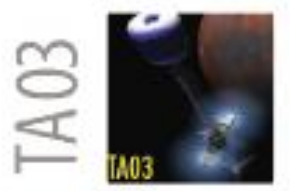

还

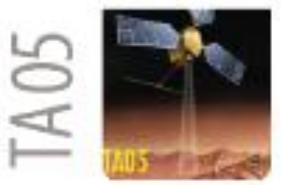

- Communication \& Navigation

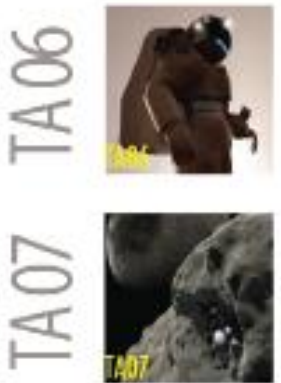

- Space Power \& Energy Storage

- Robotics, Tele-robotics \&

Autonomous Systems

- Human Health, Life Support

\& Habitation Systems

- Human Exploration

Destination Systems

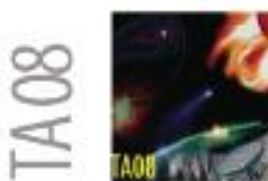

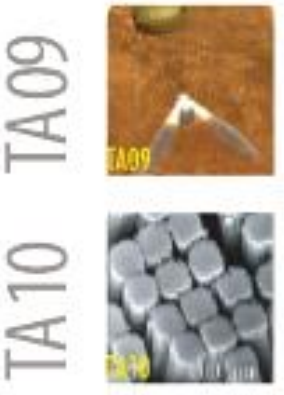

- Entry, Descent \& Landing Systems

- Nanotechnology

- Modeling, Simulation, Information Technology \& Processing

- Materials, Structures, Mechanical Systems \& Manufacturing

- Ground \& Launch Systems Processing

- Thermal Management Systems 


\title{
Space Technology Roadmap Process
}

\section{NASA Process}

\author{
8: DRAFT NASA STRs
}

OCT released draft Space Technology Roadmaps

7: Internal Reviews

to the NRC \& to the Public

Each TA Roadmap reviewed by OCT

$\&$ extended teams of subject experts

6: Roadmapping Process

Preliminary roadmaps for TA areas

5: Form Starting Point for TA Roadmaps

Assessed past roadmaps; MD \& Center inputs

4: Common Approach for TA Teams Guidelines, assumptions, deliverables

\section{3: Establish TA Teams}

OCT established NASA internal

6-member subject expert teams

for each TA, with one or two chairs

2: Identify Technology Areas

Identified Technology Areas (TAs)

1: START \& Input from MDs \& Center

Identified MD Goals, Missions,

Architectures \& Timelines;

MD Technology Roadmaps \& Prioritizations;

Center Technology Focus Areas

NASA Space Technology Roadmaps Process

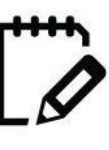

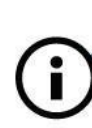

Spring 2012

\section{9: FINAL NASA}

STR REPORT

NASA to release Roadmap Report

ss
Nivi A: Establish NRC Teams

NRC Process

D $\quad \Lambda_{1}^{N} \quad$ B:Identify Common Assessment Approach

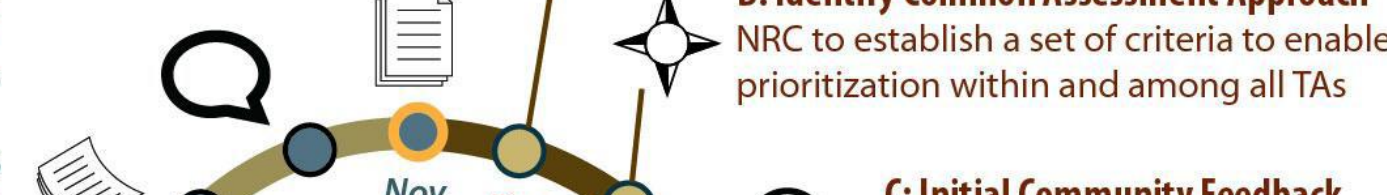

C: Initial Community Feedback

NRC to solicit external input from industry \& academia

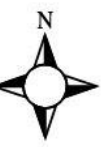
(

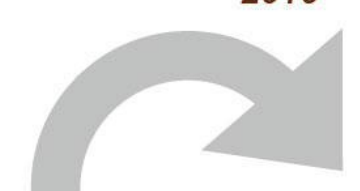

010
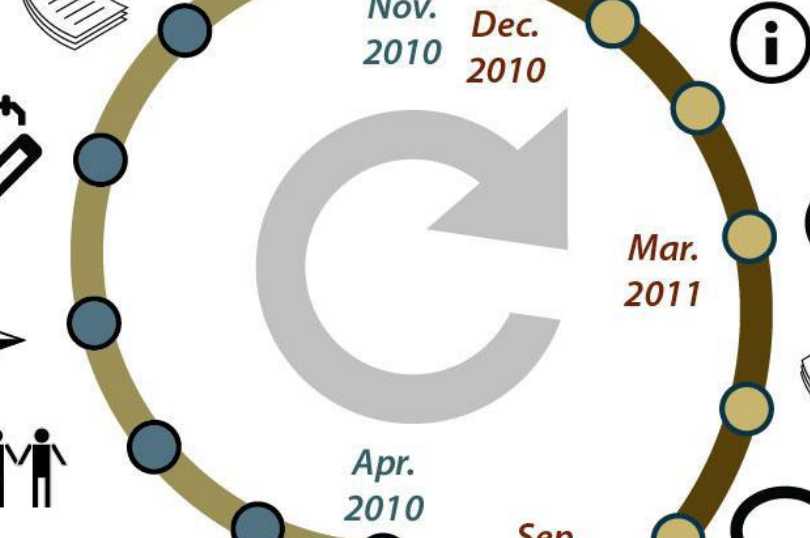

201

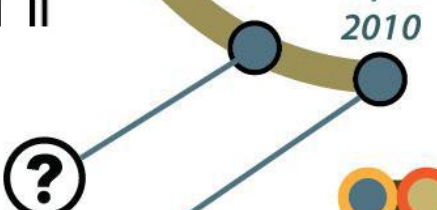

Apr.

2010

\section{D: Additional Community Feedback}

NRC to conduct public workshops

E: Deliberations by NRC Panels NRC panels meet individually to prioritize technologies and suggest improvements to roadmaps

\section{F: Documentation by NRC Panels}

NRC Panels to provide written summary to Steering Committee

\section{G: NRC Interim Findings}

NRC to release a brief interim report that addresses high-level issues associated with the roadmaps, such as the advisability of modifying the number or technical focus of the draft NASA roadmaps 2012

\section{H: FINAL NRC REPORT}

tion, including: summary of findings and recommendations for each of the roadmaps; integrated outputs from the workshops and panels; identify key common threads and issues; technologies from the TAs 


\section{Technology Area Overview}

The Scope of the roadmap includes:

- Transportation of hardware to the launch site

- Supply chain management

- Assembly, integration, and processing of the launch vehicle, spacecraft, and payload hardware at the launch site

- Transportation to and operations at the launch pad

- Launch processing infrastructure and its ability to support future operations

- Range, personnel, and facility safety capabilities

- Launch and landing weather 


\section{Technology Area Overview}

The Scope of the roadmap also includes:

- Environmental impact mitigations for ground and launch operations

- Launch control center operations and infrastructure

- Mission integration and planning

- Mission training for both ground and flight crew personnel

- Mission control center operations and infrastructure

- Telemetry and command processing and archiving

- Recovery operations for flight crews, flight hardware, and returned samples 


\section{Technology Area Overview}

- HIGH RECURRING COSTS. . . are the bane of our nation's Space Program. . . and significantly and negatively impact our ability to fulfill NASA's mission and provide low cost access to space 


\section{Technology Area Overview}

- What are the challenges and cost drivers in our current Ground and Mission operations?

- Dated, Vehicle-unique infrastructure

- Labor intensive operations ("The standing army")

- Proliferation of duplicative systems

- Lack of sufficient insight into system configuration/ system performance margins

- Low mission availability due to weather restrictions and significant maintenance/ refurbishment required between missions

- Conservative risk and safety postures 


\section{Technology Area Overview}

- Roadmap identifies ground, launch and mission technologies that will:

- Dramatically transform future space operations, with significant improvement in life-cycle costs

- Improve the quality of life on earth, and enhance the ability to explore in co-existence with the environment

- Increase reliability and mission availability using low/zero maintenance materials and systems, comprehensive capabilities to ascertain and forecast system health/configuration, data integration, and the use of advanced/expert software systems

- Enhance methods to assess safety and mission risk posture, which would allow for timely and better decision making 


\section{Key Technologies Identified}

- Low-loss cryogenic storage and transfer

- Corrosion detection and prevention

- Autonomous systems and integrated systems health management (ground systems and moving ground to onboard systems)

- Intelligent, self-diagnosing/self-healing components and systems

- Multipurpose models enabling distributed control and collaboration

- Environmental protection and remediation

- Weather effects detection and mitigation

- Ground launch assist systems

- Landing and recovery systems 
- A series of Ground and Launch Technology Demonstrations (GLTDs) would provide the means to integrate and test a bundled set of technology capabilities (a "reference architecture") into an operationally relevant environment (TRL 6/7).

- Promising and emerging technologies that are proven via GLTD could then be incorporated into upcoming test flights, referenced for the planning and development of future missions, and/or retrofitted into upgrades to existing operational capabilities. 


\section{Integrated Ground Ops Demo Unit}

- Advanced Exploration Systems is funding IGODU for 3 years

- Cryogenic propellant loading operations for the Shuttle program typically involved several large pockets of specialized engineers and managers from across the country (KSC, JSC, MSFC, Michoud and Rocketdyne).

- Cryogenic propellant operations are historically inefficient KSC and SSC lose approximately $50 \%$ of hydrogen purchased

- Current LH2 operations also consume large quantities of helium, an expensive and non-renewable resource.

- Autonomous control technologies enable future complex system operations in space with minimal mission operations support crew and reliance on system expertise availability 24/7. 


\section{IGODU Scope and Goals}

- GODU LH2:

- Reduce consumable costs associated with cryogenic propellant operations

- Demonstration of propellant handling operations (liquefaction, storage and distribution)

- GODU LO2:

- Reduce "standing army" of engineers associated with maintaining and operating ground systems through the use of health management and autonomous control technologies 


\section{IGODU Identified Customers}

- Ground Systems Development and Operations (GSDO) is looking at Integrated Refrigeration and Storage technologies to lower life cycle costs and solve propellant quantity availability issues

- United Launch Alliance interested in propellant conditioning to support future manifest

- Soldier/Warfighter Operationally Responsive Deployer for Space (SWORDS) - Army small satellite launch program

- Potential to demonstrate IGODU autonomous control technologies on flight test opportunities in FY14 


\section{Other GSDO Investments}

- Ground Systems Development and Operations (GSDO) has the responsibility of managing two significant development and modernization efforts: Exploration Ground Systems and 21 $1^{\text {st }}$ Century Space Launch Complex (21CSLC)

- 21CSLC initiative is a focused set of investments to repair, upgrade, and modernize the infrastructure at KSC to support multiple users (commercial and government) of KSC facilities and services.

- Develop effective environmentally friendly coatings for launch equipment and chemical treatments to neutralize hypergolic fuels to an inert state

- Advanced Ground Systems Maintenance - Fault Detection, Isolation, and Recovery; Prognostics; Smart Sensors 


\section{Investment Plan}

- The Draft Strategic Space Technology Investment Plan (SSTIP)

was developed based upon the NASA Space Technology

Roadmaps, NRC recommendations, technology portfolio assessments, technology needs input from stakeholders, National Space Policy, and Office of Management and Budget Science and Technology Priorities.

- Each pillar of the SSTIP comprises a strategic technology investment goal, three to five associated capability objectives, and technical challenges that underpin those objectives. 


\section{SSTIP Pillars}

- The first three pillars represent investments required for NASA's scientific, robotic, and human exploration missions. The fourth pillar represents space technology needs identified by NASA's stakeholders, including other Government agencies, international partners, and private industry.

- Pillar 1 Goal: Extend and sustain human presence and activities in space

- Pillar 2 Goal: Explore the structure, origin, and evolution of the solar system, and search for life past and present (in situ measurements)

- Pillar 3 Goal: Expand understanding of the Earth and the universe (remote measurements)

- Pillar 4 Goal: Energize domestic space enterprise and extend benefits of space for the Nation 


\section{GLSP in SSTIP}

- Ground and launch system technology advances are mentioned under Pillar 1: Extend and sustain human presence and activities in space

- Capability objective: To enable transportation to, from, and on planetary bodies.

- Improvements in launch ground systems will help missions run more efficiently and affordably, which becomes more important as new missions demand specific launch windows, such as missions to a nearEarth asteroid (NEA). More efficient ground and launch processing systems must reduce the overall mission lifecycle cost, to enable NASA to meet its mission within the constrained budget environment.

- The SSTIP includes GLSP technologies as complementary technology investments with the primary benefit to reduced costs. 


\section{Summary}

- Ground and Launch Systems Processing Technologies enhance life on earth AND have a major impact on how we access

space

- GLSP Technologies are also directly applicable to building and manufacturing industries, weather forecasting, defense/homeland security, oil and gas industries, energy, hazardous operations

- Can feasibly provide the cost breakthroughs to realize routine, commercial space access

- The NRC concluded that advanced technologies can contribute to solving the challenges of reducing the cost of maintaining and operating ground control and launch infrastructure, improving safety, and improving the timeliness, relevance, and accuracy of information provided to ground control and launch personnel. 